\section{A CASE OF SPONTANEOUS RUPTURE OF THE HEART:*}

By JOHN GORDON, M.D., Assistant Physician, Aberde€n Royal Infirmary.

Spontaneous rupture of the heart is by no means a common occurrence. That being so, I thought it would be interesting to bring together the notes of this case, which I confess I was unable, either by percussion or by auscultation, to diagnose as a ruptured heart. The true nature was only shown by the post-mortem examination.

Previous History.-C. A., the subject of the following notes, was an unmarried female, aged 72, a well-nourished, fresh-complexioned, and on the whole well-pleased, smiling pauper inmate of the poorhouse. She had shown for some time previous to the latal attack symptoms of senile dementia. She was troubled with "excessive salivation, and was familiary

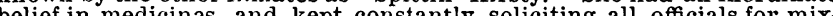
belief in medicines, and kept constanty soliciting all oncials for mixtures. hie reason she woul give or whing a mixture "was " either some stomat she made the request without framie, or he "spit, but as often fact, she had good appetite and digestion, and her cough, when slee had fact, she has of the most trivial character.

History of last Illness - On June $x$ th, at $\mathrm{x}$ o'clock, she partook with her Helory usual appente of a hearty meal of soup and full sushite. Suddenly regained consciousness was supplied with a ounces of whisk but fainted regain gandition She recovered a little about 3 .3. was able to talk, and complained of pain across her chest and stomach.

Symptoms and Physdcal Signs - She was seen by me about 6 . first romark as useal was "Give me sen by me about " P.M., and he cos complain ' restless, but quite able and willing to talk The temperature was sub restless, but quite able and willing to talk. The temperature was subnormal, the pulse was small and soft, 120 per minute, the respirations planation of her condition. I ordered poultices and an opiate, with light plana.

Death. - The patient's condition continued much as indicated until June 2oth, when at ro P.M. she suddenly complained of intense pain-again across the chest. At this time she was evidently in great distress. moaning and crying out, a face of agony, profuse perspiration, extrem restlessness, and a quick, small pulse, 140 per minute. This condition, or less until 6 A.M., after which she became quieter. During the day she revived somewhat, but kept in a semi-unconscious condition. she revived somewhat, but kept in a semi-unconscious condition. She pulse very small (130 to r40), the extremities cold, and she died at ro.45 on the morning of June $22 \mathrm{nd}$.

Necropsy.-Dr. George M. Duncan, Assistant Pathologist in Aberdeen University, kindly performed the post-mortem examination with me, and I have to thank liim for the following notes illustrative of the case. The pericardial sac when opened was found to be distended witl dark gelatinous blood clot. On lifting up the apex of the heart a small ragged glit about a quarter of an inch long could be seen on the posterio surface of the left ventricle an inch below the auriculo-ventricular groove, and a quarter of an inch to the left of the interventricular groove, The ascending and transverse portions of the aorta were much dilated, but the competency of the aortic valve, tested by water after removal of the heart. was not impaired. The aortic cusps ap peared to be normal, but the walls of the vessel were markedly atheromatous, both coronary arteries were extremely atheromatous and tortuous, and could be felt standing out like rigid cords in the epicardial fat. On opening the right coronary artery a small thrombus was found completely blocking the branch of the vessel which passes along the posterior interventricular groove, and supplies the seat of the rupture. The left ventricle was filled with dark fibrinous blood clot. Its wall was somewhat flabby, but there were no signs of fatty degeneration, except at the part where the rupture took place. There was a ragged slit in the posterior wall about $\frac{1}{4}$ inch from the interventricular septum and $x$ inch below the edge of the aortic valve. This slit measured nearly $\frac{3}{4}$ inch in length; its edges were soft and friable. The opening was plugged by a small fibrinous clot. Lungs slightly œedematous and congested; liver, spleen,

It may be as well to recall again the fact that the patient was practically an insane person, that the description of her ailments by no means tended to clear up any point of difficulty, and that the first set of symptoms might quite possibly have been mistaken for some gastric disturbance although very soon the diagnosis that I was inclined to form was that of angina pectoris.

An interesting point in the history of the case is the time at which the actual rupture of the heart may have taken place. In my opinion the first onset of symptoms may have been caused by the small thrombus which completely blocked the branch of the right coronary artery, since after this onset the patient recovered very considerably, was able to take food, to engage in conversation, and complained only of pain in the chest.
I am inclined to assign the actual rupture of the heart to June 20 th at IO P.M. when the patient was suddenly seized with agonising pains in the chest. After a night of extreme pain there followed at 6 A.M. that state of collapse from which she did not again recover.

If these opinions be accurate, it follows that from the occurrence of the thrombus on June i th at 2 P.M., there existed a period during which a branch of the coronary artery was prevented from nourishing its part of the left ventricle. During that period it may be supposed that the degenerative changes began in the muscular tissue, and that this weakened condition led to the spontaneous rupture of the left ventricle at that part. It has to be remembered that the branches of the coronary arteries are in great part terminal in their distribution, and that any stoppage to their circulation means a non-compensated interference with the part of the heart specially affected.

The period of local degeneration in this case included three days and eight hours, and this period represents the length of time during which the muscular tissue of the heart which had been deprived of its blood supply was still able to assist in carrying on the heart's function.

The period the patient lived after the rupture was one day, twelve hours, forty-five minutes. The interest in this has reference to the fact that the majority of cases die suddenly. Only in rare instances do the patients survive a day. It is stated that spontaneous rupture occurs mostly in the front of the left ventricle, whereas in this particular case rupture took place on the posterior surface.

The only other case of rupture of the heart that has come under my personal observation was in a male, and males are supposed to be more liable to it than females.

\section{ME M O RAN DA: \\ MEDICAL, SURGICAL, OBSTETRICAL, THERA- PEUTICAL, PATHOLOGICAL, Ėtc.}

\section{PROBABLE PERSISTENCE OF THYRO-GLOSSAI DUCT.}

Is Professor Murray's Goulstonian Lecture on the Pathology of the Thyroid Gland, published in the British MEdical JournaL of March inth, there are some remarks on the nonpersistence of the thyro-glossal duct. In this connection, the following case I thought not without interest.

In September, 1898, whilst on a professional visit twentyfive miles from here, I was called in to see D. K., a woman aged 2I, with enlarged thyroid gland. For some months she had complained of an offensive discharge into her throat, without vomiting or coughing it up, and with no accompanying catarrh. Sometimes this becomes quite profuse, and on such occasions she remarked a diminution in the size of thyroid enlargement. Firm compression on the gland produced such a discharge in the throat. The patient said it had resisted medical treatment for some months.

It occurred to me that it might be a persisting thyro-glossa duct from the median lobe of the thyroid gland, and I asked her to come to my surgery here for further examination and treatment, but in the meantime placed her on inunctions of lanolin and iodoform over the thyroid gland. About a month after I heard from her that this had completely cured the offensive discharge, but as to any variation in the goitrous condition I have not heard.

J. W. McIntosh, B.A., M.B.,

Coroner for Manitoulin, Medical Superintendent to the Indians. Manitowaning, Ont., Canada.

\section{ERYTHROL TETRANITRATE IN ANGINA} PECTORIS.

In this drug we have, I believe, a remedy superior even to " nitroglycerine," its effects being very rapid and more lasting. A man, 52 years of age, had good health until about three and a-half years ago, when he rapidly developed serious signs of heart failure. He had taken a good deal of whisky for some time previous to the commencement of his illness, and in addition to his cardiac trouble had cirrhosis of the liver. He 